\section{A classic genetic text about classic genetic texts}

Landmarks in medical genetics. Classic papers with commentaries

Peter S Harper. Oxford University Press, Oxford, 2004.

Pa..............

Patrick j Morrison

European Journal of Human Genetics (2005) 13, 892.

doi:10.1038/sj.ejhg.5201417

$\mathrm{P}$ rofessor Sir Peter Harper has recently retired as a clinical geneticist and head of the Medical Genetics Department in Cardiff, United Kingdom. He is in an ideal position to write this book in that he is young enough to remember the end of the early clinical era of genetics in the 1970s, and known and worked with many famous founders in genetics and old enough to have lived through the many advances in this book that have happened in the last 30-40 years.

I was expecting a book packed with facsimile reproductions of old dusty papers in genetics but this is a refreshing book with original classic papers reproduced in modern format each accompanied by an insightful commentary placing the paper in context. The loss of not including the facsimile reproduction of each of the original papers is small instead of varied fonts that are practically illegible in the older papers in the 1930s and 1940s, we have crisp consistent modern fonts and in some cases, translations from the original German and French. The clarity of the modern transcription of the texts gives an easy read and the book is neatly split into eight sections - the first, contains classic descriptions of genetic disorders including that by Huntington, in 1872, of Huntington's disease, and Osler of hereditary haemorrhagic telangiectasia in 1901. Harper is not afraid to criticise the accounts or praise the conciseness where appropriate. The original description of Duchenne muscular dystrophy is given as Meryon's account as he was the first to describe the disorder. Duchenne's paper is a difficult read and although the text from Duchenne's paper is not included, Harper usefully combines the excellent pictures from Duchenne's account with the text from Meryon to give an excellent synthesis of the history. All these accounts come alive with the fresh restored text and the commentaries by Harper with observations and snippets of information about the writers that are superb. Other sections include Mendelian inheritance, chromosome disorders, human gene mapping, biochemical genetics, variation in Mendelian inheritance and management of genetic disease.

Two papers included at the end on 'genetics society and medicine' are a starter for someone to edit a second historical book on the important societal advances and changes in genetics - the subject matter of which would be too extensive for this book and the increasing importance of documenting the developments in this area merits such a book.

Some of the accounts portray the excitement of the realisation that there are 46 human chromosomes, and others outline the long journey to isolating and cloning genes - for example, the Huntington's disease gene being quickly localised on chromosome 4 , but then another
10 years before actual identification. Recent advances are also included - the 1980 paper on periconceptual vitamin supplementation on the prevention of neural tube defects was a landmark in prevention. I can remember in the late 1980s dealing with genetic clinics full of cases of spina bifida - a problem we now rarely see in this century. How history, even 20 years ago, has influenced our practice today.

Some of the accounts are humbling the paper by Julia Bell and JBS Haldane on haemophilia includes cases where one patient had 'bleeding so severe as to soak through the mattress and drip onto the floor.' Levels of healthcare have changed significantly for the better since 1937 . The same paper also mentions difficulties with family quarrels and lack of cooperation in one case where Bell and Haldane tried to visit at home where they were 'not admitted to his house' - some things do not change!

Landsteiner's paper on blood transfusion gives insights into possible forensic uses of paternity testing and also details the massive loss of life by unmatched transfusions before blood grouping was available.

Harper presents a vivid and gripping series of papers, which should be read by all clinicians and scientist in genetics to get an idea of how the specialty has evolved with time. This book will save pouring over old dusty papers produced years ago by people that modern students may never have heard of, but there are many lessons that have been learnt and we too can try and learn from some of the mistakes and at the same time be encouraged by the enthusiasm and insightfulness of our predecessors. Every genetics department should have a copy of this book and it should be compulsory reading for new trainees

Patrick J Morrison is at the Department of Medical Genetics, Belfast City Hospital Trust, Belfast BT9 7AB, UK. E-mail: patrick.morrison@bch.n-i.nhs.uk 